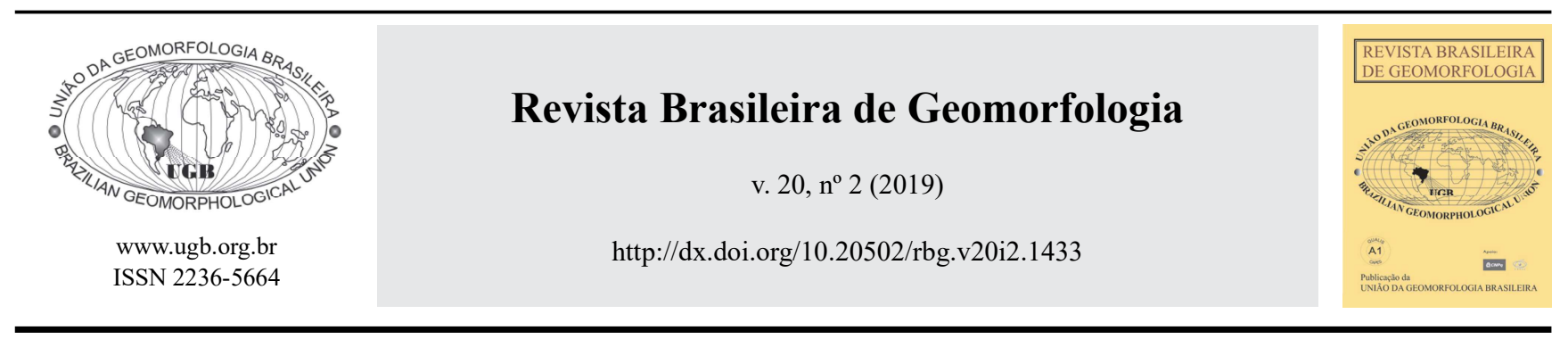

\title{
CARACTERIZAÇÃO GEOMORFOLÓGICA DAS ÁREAS LIVRES DE GELO NA MARGEM LESTE DO CAMPO DE GELO WARSZAWA, ILHA REI GEORGE, ANTÁRTICA MARÍTIMA
}

\section{GEOMORPHOLOGICAL CHARACTERIZATION OF ICE-FREE LAND AREAS IN THE EAST MARGIN OF WARSZAWA ICE FIELD, KING GEORGE ISLAND, MARITIME ANTARCTICA}

Cleiva Perondi

Programa de Pós-Graduação em Geografia, Universidade Federal do Rio Grande do Sul Av. Bento Gonçalves, 9500, Porto Alegre, Rio Grande do Sul. CEP: 91.540-000. Brasil ORCID: orcid.org/0000-0003-2202-2721 E-mail: cleivaperondi@gmail.com

Kátia Kellem da Rosa

Programa de Pós-Graduação em Geografia, Universidade Federal do Rio Grande do Sul Av. Bento Gonçalves, 9500, Porto Alegre, Rio Grande do Sul. CEP: 91.540-000. Brasil ORCID: orcid.org/0000-0003-0977-9658

E-mail:katia.rosa@ufrgs.br

Rosemary Vieira

Programa de Pós-Graduação em Geografia, Universidade Federal do Rio Grande do Sul Av. Bento Gonçalves, 9500, Porto Alegre, Rio Grande do Sul. CEP: 91.540-000. Brasil ORCID: orcid.org/0000-0003-0312-2890

E-mail: rosemaryvieira@id.uff.br

\section{Informações sobre o Artigo}

Recebido (Received):

22/12/2018

Aceito (Accepted):

$15 / 03 / 2019$

\section{Palavras-chave:}

Processos Geomorfológicos Glaciais; Mudanças Ambientais Glaciais; Sistema Proglacial.

\section{Keywords:}

Glacial Geomorphological Processes; Glacial Environments Changes; Proglacial Systems.

\section{Resumo:}

O objetivo deste trabalho é identificar as feições deposicionais de mesoescala marginais ao gelo e os processos geomorfológicos relacionados aos ambientes proglaciais das geleiras Ecology, Sphinx, Baranowski, Tower e Windy, localizadas na margem leste do campo de gelo Warszawa na Ilha Rei George, Antártica $\left(62^{\circ} 12^{\prime} 0^{\prime \prime} \mathrm{S}-58^{\circ} 30^{\prime} 0^{\prime} \mathrm{W}\right)$. A análise geomorfométrica, através do TANDEM-X de resolução espacial de $8 \mathrm{~m}$, possibilitou verificar que há o predomínio das classes de elevação entre 100 e $200 \mathrm{~m}$ na área total de estudo, as áreas livres de gelo correspondentes as geleiras Tower e Sphinx possuem os maiores valores de declividade. O mapeamento geomorfológico das áreas livres de gelo foi obtido através da análise visual em imagens Sentinel-2 (verão 2018) e WorldView-2 (verão 2014). A retração das geleiras tem levado a formação de ambientes proglaciais dinâmicos, com exposição de geoformas, como morainas laterais, frontais de recessão, latero-frontais, eskers, além de corpos hídricos como lagos e lagunas, canais de drenagem entrelaçados ou não. As formas de relevo deposicionais glaciais estão sob influência da alta atividade paraglacial. O 
ambiente proglacial apresenta uma completa transição paraglacial, há predomínio conforme se distancia das margens frontais das geleiras (ambientes proglaciais II e III), pois a influência glacial é predominante na paisagem na margem das geleiras (ambiente proglacial I). As geleiras Tower e Sphinx possuem os ambientes I de menores dimensões, devido ao perfil mais íngreme. As feições mapeadas resultaram na reconstrução glacial e a descontinuidade da moraina latero-frontal mais externa evidenciaram condições de término marinho para todas as geleiras.

\begin{abstract}
:
The work aims to identify the ice-marginal depositional landforms and the geomorphological processes in proglacial environments of the Ecology, Sphinx, Baranowski, Tower and Windy glaciers (east-flowing land-terminating glaciers of the Warszawa Ice cap), Admiralty Bay coast, King George Island, South Shetlands, Maritime Antarctica $\left(62^{\circ} 12^{\prime} 0^{\prime \prime} \mathrm{S}-58^{\circ} 30^{\prime} 0^{\prime \prime} \mathrm{W}\right)$. Geomorphometrical analysis were carried out using a 8 meters TanDEM-X Digital Elevation Model (DEM) and it was evidenced a predominance of elevation classes between 100-200 m. The Tower and Sphinx proglacial areas has highest slope values. The geomorphological mapping of glacial, glaciofluvial and glaciolacustre landforms of ice-free land areas was obtained with visual analysis of Sentinel-2 (2018) and WorldView-2 (2014) images. A dynamic proglacial environment is derived of the glacial retreat processes, and reveals different landforms, such as lateral, recession frontal, lateral-frontal moraines, eskers, lakes, lagoons and drainage channels. The recent ice-free land areas are susceptible to paraglacial (non-glacial) processes. The proglacial environment presented a complete paraglacial transition, leaving several environments (I-III: more to less glacial action) with distances from the glacier margins. The Tower and Sphinx glaciers have the smallest area in I environment due their steeper profile. The mapped features resulted in the glacial reconstruction and the discontinuity of the outermost lateral-frontal moraine evidenced marine termination conditions for all the glaciers.
\end{abstract}

\section{Introdução}

A Criosfera é observada para o entendimento da dinâmica dos ambientes e para detectar os impactos da tendência a aquecimento troposférico. As geleiras são sensíveis às mudanças climáticas e respondem com o balanço negativo de massa para a região da península Antártica. A retração das geleiras tem revelado um novo ambiente, o ambiente proglacial, no qual há processos glaciais, paraglaciais e periglaciais.

A área livre de cobertura de gelo no setor frontal de uma geleira em retração forma a área proglacial. Esse ambiente possui feições deposicionais no relevo, que registram informações indicativas do padrão de deglaciação, da direção de fluxo, entre outros processos, como seu avanço ou recuo, espessura e padrão de retração (NAPIERALSKI et al., 2007; BENN \& EVANS, 2010). Os processos paraglaciais se configuram por não sofrerem ações glaciais, opera em uma paisagem pós-glacial, sendo influenciados por processos eólicos e hídricos, por exemplo (BALLANTYNE, 2002). Não são definidos por sua localização e sim por sua modificação de ambiente glacial para não-glacial. Os ambientes periglaciais são caracterizados pela influência da ação do gelo, presença de permafrost (SLAYMAKER, 2011) e pode ser classificado como uma zona de transição entre o não-glacial e glacial (FERREIA, 1991). Pouco se sabe dos impactos das mudanças climáticas nas geleiras e no sistema geomorfológico proglacial.

O mapeamento geomorfológico possibilita compreender os processos que ocorrem superficialmente e que registram a evolução da paisagem (OTTO \& SMITH, 2013). Contribui para a interpretação de processos deposicionais, estudos comparativos com outros ambientes glaciais para a construção de cenários futuros (ROSA, 2012). Ao analisar as feições em áreas livres de gelo é possível obter informações sobre a dinâmica glacial, e mapeá-las é uma técnica importante para pesquisas em regiões glaciais (HUBBARD \& GLASSER, 2005).

Os dados gerados a partir do Sensoriamento Remoto, como os Modelos Digitais de Elevação, por exemplo, são importantes ferramentas que auxiliam a detectar e monitorar processos geomorfológicos glaciais, bem como, melhorar os métodos para estudos de análises superficiais (OTTO \& SMITH, 2013). Autores como Hattestrand et al. (2007), Glasser et al. (2011), Rosa et al. (2011), Andrade (2013), Simões (2017), Bonada et al. (2018), Petsch (2018) entre outros, utilizam produtos originados do Sensoriamento Remoto para identificar feições de relevo proglaciais e evidenciar as características e processos geomorfológicos relacionados à dinâmica das geleiras. 
Mapear as feições de relevo em ambientes livres de gelo e entender a evolução destes na margem leste do campo de gelo Warszawa, ilha Rei George (IRG), é relevante, pois evidencia características atuais e pretéritas das geleiras Ecology, Sphinx, Baranowski, Tower e Windy. Formas de relevo, geradas pela ação glacial, podem ter origens diferenciadas e compreendê-las auxilia na reconstituição da evolução recente das geleiras, assim como mudanças na direção de fluxo e regime termal (BENNET \& GLASSER, 1996). O mapeamento geomorfológico e a base de dados em SIG poderá ser disponibilizada à comunidade científica, através do GLIMS Glacier Database. Os resultados poderão prover a continuidade do monitoramento ambiental e investigação da evolução das feições deposicionais glaciais diante dos processos paraglaciais e retração da geleira, assim como, obter os indicadores de mudanças e registrar os ambientes deposicionais mais dinâmicos.

O objetivo deste trabalho é identificar as feições deposicionais de mesoescala marginais ao gelo e os processos geomorfológicos relacionados aos ambientes proglaciais das geleiras Ecology, Sphinx, Baranowski, Tower e Windy.

\section{2. Área de Estudo}

As geleiras da área de estudo Ecology, Sphinx, Baranowski, Tower e Windy, bem como, suas áreas livres de gelo, estão localizadas na margem leste do campo de gelo Warszawa, na ilha Rei George, Antártica Marítima (Figura 1).

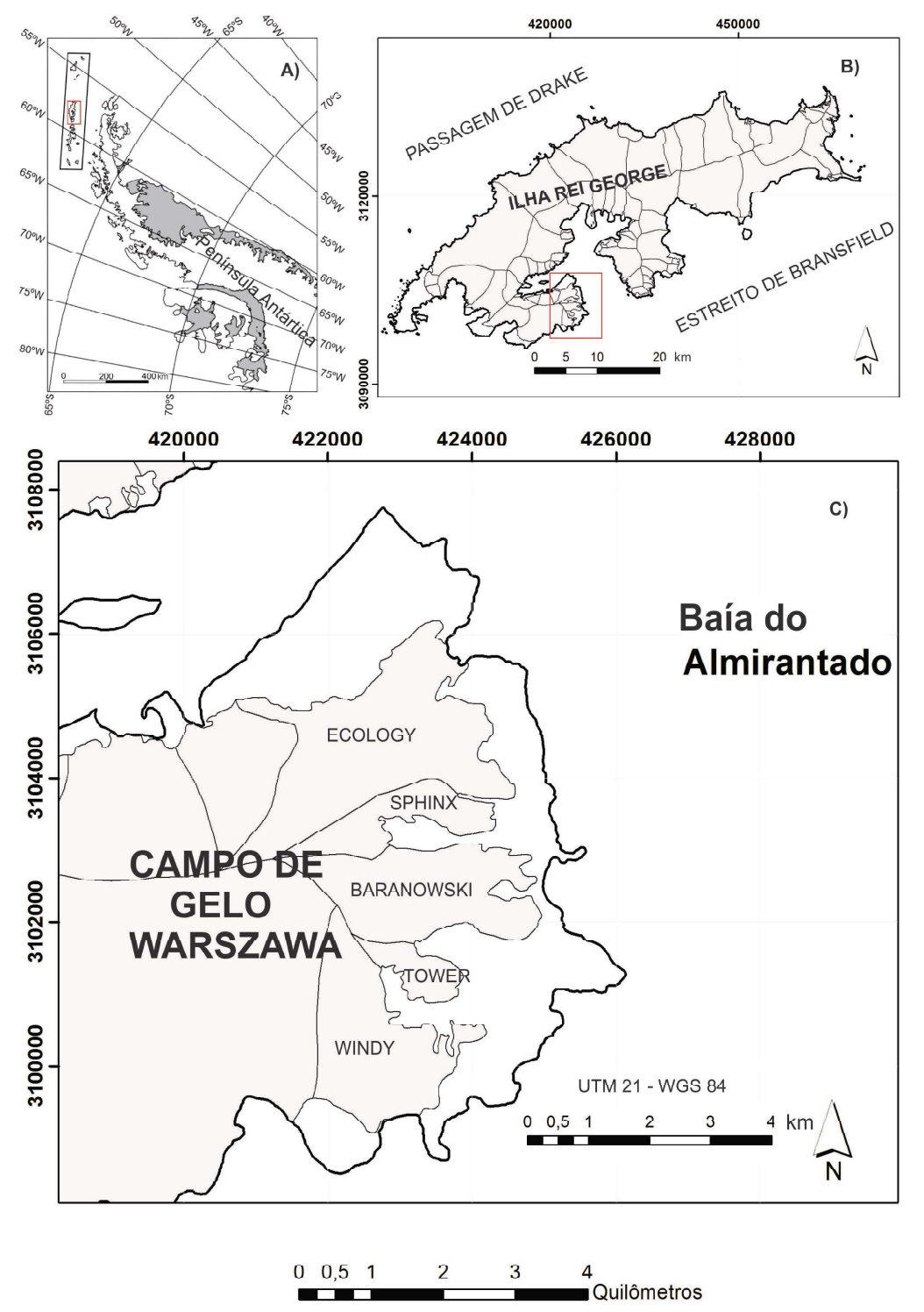

Figura 1 - (a) Localização da Península Antártica, (b) Localização da costa leste do campo de gelo Warszawa, (c) Localização das geleiras Ecology, Sphinx, Baranowski, Tower e Windy e suas áreas livres de gelo. 
O embasamento rochoso da ilha Rei George possui uma formação de idade que se estende desde o Pré-Cambriano ao Paleogeno e Neogeno, constituído por rochas metassedimentares e vulcânicas intrusivas e, mais recentemente, por rochas sedimentares. Sua litoestratigrafia contém sedimentos do Paleozoico Superior, em alguns casos metamorfizados, devido a processos vulcânicos ocorridos no Jurássico e do Paleógeno ao Neógeno (CURL, 1980; BIRKENMAJER, 1980a; BIRKENMAJER, 1991). A predominância litológica é de rochas básicas como basaltos, por exemplo, que podem ser encontrados em diversas fases de alteração. Há processos de metamorfismos de baixa pressão que propiciam a formação de minerais como clorita e calcita entre outros (THOMSON et al., 1983).

A atividade vulcânica expressiva na IRG durante o Jurássico Superior pode ser percebida pelas camadas de basalto e andesitos, mescladas por rochas vulcanoclásticas ligadas a subducção meso-cenozóico do assoalho do Oceano Pacífico, abaixo da Península Antártica (BIRKENMAJER, 1980a).

A ilha Rei George situa-se em área tectonicamente ativa, que desde o Oligoceno está sujeita a diversas glaciações e também a movimento glacio-eustáticos (BIRKENMAJER, 1991). A ilha consiste em vários blocos tectônicos separados, com direção leste - nordeste e oeste - noroeste. Essa configuração é representada por terrenos desarticulados entre si e com distância ignorada (BIRKENMAJER, 1997). Estes terrenos são cruzados por sistemas de falhamentos que apresentam tendência noroeste-sudeste (BIRKENMAJER, 1989). O campo de gelo Warszawa (WB) está associado a estas falhas, já que se originou da Falha Ezcurra (BIRKENMAJER, 1983). Braun (2001) considera o Bloco Warszawa como uma unidade geológica, que possui em sua composição rochas vulcânicas metamorfoseadas (BIRKENMAJER, 1980b), com idade de 77 e 37 milhões de anos (GROENEWEG \& BEUNGK, 1992). O Bloco Warszawa é caracterizado por Tokarski (1987) como um composto de rochas vulcânicas as quais sofreram metamorfismo.

O relevo irregular apresentado por áreas livres de gelo na margem oeste da Baía do Almirantado, na Ilha Rei George, Antártica, são determinadas por sua capacidade de resistência à erosão, com feições de atividades vulcânicas, estreitamente relacionadas a glaciações anteriores (RACHLEWICZ, 1999).

\section{Materiais e Métodos}

A análise geomorfométrica foi realizada com dados do TanDEM-X (2012), obtidos através da Agência Espacial Alemã (DLR), de 10 metros de resolução espacial e acurácia vertical relativa de 2-4 metros (declividade de $\leq 20 \%$ e declividade de $>20 \%$ respectivamente) e absoluta menor de 10 metros (WESSEL, 2018). Foram produzidos mapas de hipsometria, de declividade, de aspecto e um modelo de sombreamento dos ambientes livres de gelo da margem leste do campo de gelo Warszawa, utilizando o 3D Analyst do ArcGIS ${ }^{\circ}$.

O mapa hipsométrico foi elaborado a partir do fatiamento do Modelo Digital de Elevação em diferentes classes. As áreas absolutas e relativas de cada classe do mapa hipsométrico, de declividade e orientação das vertentes (drenagens) foram quantificados no programa ArcGISTM.

O mapeamento geomorfológico proglacial envolveu a identificação das feições deposicionais glaciais de meso-escala nas imagens WorldView-2 de 2014 (Fevereiro) e Sentinel-2 (Fevereiro) de 2018. A geração e análise de dados morfométricos, perfis topográficos, identificação de formas e processos realizados durante a Operação Antártica (OPERANTAR XX), também auxiliaram na interpretação e mapeamento. Baseados em critérios de classificação e mapeamento das formas de relevo de Hambrey (1994), Bennett \& Glasser (1996), Benn \& Evans (2010) e Davies et al. (2014), foi realizado o mapeamento de feições deposicionais glaciais de mesoescala.

Com base no mapa geomorfológico foi evidenciada a sequência cronológica da formação de depósitos ligados ao padrão de retração glacial. Para a determinação dos ambientes proglacial marginal ao gelo, proglacial distal e proglacial com predominância da atividade paraglacial e periglacial, considerou-se a distância da margem glacial e os processos geomorfológicos proglaciais, paraglaciais e periglaciais. Esta metodologia foi baseada em estudos de reconstrução do ambiente glacial que utiliza como indicador a disposição espacial de formas de relevo, como morainas, concluindo sobre o processo de avanço e recuo das geleiras (BOULTON et al., 1985; PUNKARI, 1995; CUFFEY et al., 2000; KLEMAN, 2006). 


\section{Resultados e Discussões}

4.1 Geomorfometria da margem oeste da Baía do Almirantado na Ilha Rei George

Aárea de estudo possui elevação média do terreno de $173 \mathrm{~m}$, com desvio padrão de $107 \mathrm{~m}$ (Figura 2a e Tabela 1).
As classes de elevação (em metros) com maiores áreas se apresentam entre 100-200m, representando 33\% da área de estudo; seguida pela classe $0-100 \mathrm{~m}$, a qual abrange $29 \%$; a classe $200-300 \mathrm{~m}$ abrangendo $24 \%$ da área de estudo, e subsequente as classes $300-400 \mathrm{~m}, 400-500 \mathrm{~m}$, representando respectivamente $9,2 \%$, e 3,7\% da área total (Tabela 1 ).

Tabela 1: Áreas absolutas e relativas e estatísticas das classes do mapa hipsométrico referente à margem leste do campo de gelo Warszawa.

\begin{tabular}{|c|c|c|c|}
\hline \multicolumn{2}{|c|}{ ELEVAÇÃO (M) } & ÁREA $\left(K^{2}\right)$ & ÁREA (\%) \\
\hline \multicolumn{2}{|c|}{$0-100$} & 7,9 & 29 \\
\hline \multicolumn{2}{|c|}{$100,0000001-200$} & 9 & 33 \\
\hline \multicolumn{2}{|c|}{$200,0000001-300$} & 6,5 & 24 \\
\hline \multicolumn{2}{|c|}{$300,0000001-400$} & 2,5 & 9,2 \\
\hline \multicolumn{2}{|c|}{$400,0000001-500$} & 1 & 3,7 \\
\hline \multicolumn{4}{|c|}{ ESTATÍSTICAS (M) } \\
\hline Mínima & Máxima & Média & Desvio Padrão \\
\hline 0 & 455 & 173 & 107 \\
\hline
\end{tabular}

Tabela 2: Áreas absolutas e relativas e estatísticas das classes do mapa de declividade referente à margem leste do campo de gelo Warszawa.

\begin{tabular}{|c|c|c|c|}
\hline \multicolumn{2}{|c|}{ Declividade } & \multicolumn{2}{|c|}{ Margem leste do campo de gelo Warszawa } \\
\hline Tipo de relevo & $(\%)$ & Área $\left(\mathbf{k m}^{2}\right)$ & Área (\%) \\
\hline Plano & $0-3$ & 0,6 & 2,2 \\
\hline Suave ondulado & $3,1-8$ & 3,4 & 12,6 \\
\hline Ondulado & $8,1-20$ & 13,22 & 48 \\
\hline $\begin{array}{l}\text { Fortemente } \\
\text { Ondulado }\end{array}$ & $20,1-45$ & 7,1 & 26 \\
\hline Montanhoso & $45,1-75$ & 1,7 & 6,3 \\
\hline \multicolumn{4}{|c|}{ ESTATÍSTICAS (\%) } \\
\hline Mínima & Máxima & Média & Desvio Padrão \\
\hline 0 & 820 & 21 & 29 \\
\hline
\end{tabular}

As áreas de maior elevação na margem leste do campo de gelo Warszawa estão localizadas em setores constituídos predominantemente por geleiras; mas também podem ser encontradas em setores com exposição de rochas, como por exemplo, na bacia da geleira Baranowski. O Nunatak Siodlo é circundado pela geleira Baranowski, o Pico Pawson está entre as geleiras Ecology e Sphinx e a Escarpa Anvil está entre as geleiras Sphinx e Baranowski. Estes constituem exemplos de picos rochosos de maior elevação na área de estudo.

A classe de declividade de maior predominância na área de estudo é Ondulado, representando 48\%; seguido pela classe de relevo Fortemente Ondulado, com 26\% da área. Os dados estatísticos mostram que as áreas com declividade máxima correspondem a $820 \%$, média de 21 $\%$, com desvio padrão de 29\% (Figura 2 b e Tabela 2).

As geleiras Windy e Tower possuem declive acentuado em suas áreas livres de gelo (0 a >75\%). As áreas declivosas coincidem com áreas rochosas expostas, como o Pico The Tower e Brama. Na geleira Baranowski, as áreas menos declivosas estão localizadas próximas a Baía do Almirantado. 

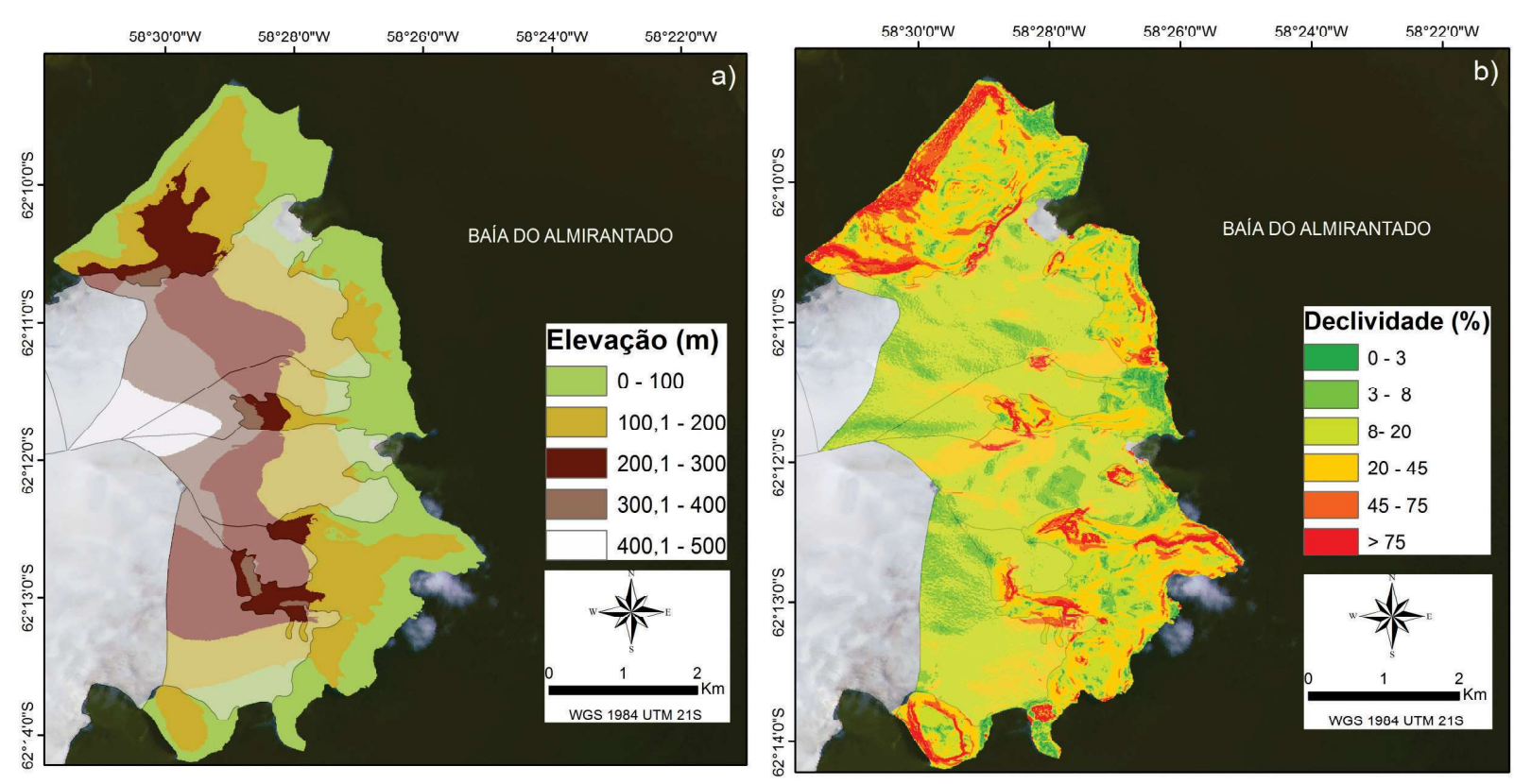

Figura 2 - (a) Mapa hipsométrico, (b) Mapa de declividade da margem leste do campo de gelo Warszawa (Fonte: Rosa et al., 2014).

As geleiras Baranowski, Sphinx e Ecology possuem gradiente de declive suavizado em relação às geleiras Tower e Windy. A área livre de gelo da geleira Ecology apresenta alta variação de declive $(0 \%$ a $75 \%)$. Suas vertentes estão voltadas principalmente à Nordeste. A área livre de gelo da geleira Sphinx apresenta declives de até $20-45 \%$, com vertentes orientadas à Leste, Noroeste e Oeste. A área livre de gelo da geleira Baranowski apresenta declividade entre $0-75 \%$, mas os maiores percentuais estão no setor do Monte Siodlo.

\subsection{Geomorfologia dos ambientes proglaciais}

Devido à retração frontal das geleiras Ecology, Sphinx, Baranowski, Tower e Windy, evidenciada por Perondi (2018), houve aumento de áreas sem cobertura de gelo, expondo dessa forma os depósitos glaciais. Estas formas de relevo documentam a configuração antiga da geleira e seu histórico de deglaciação.

Foram identificadas na área proglacial das geleiras Ecology, Sphinx, Baranowski, Tower e Windy (Figuras 3-7): morainas frontais, laterais e latero-frontais, eskers, canais entrelaçados, lagos e lagunas, além de núcleos de vegetação em setores distais às geleiras. O detalhamento das feições e processos estão na Tabela 3 .

Foram evidenciados três ambientes distintos nas áreas livre de gelo: ambiente proglacial mar- ginal ao gelo, denominado I, ambiente proglacial distal, denominado II, e o ambiente proglacial com processos paraglaciais e periglaciais predominantes. Nem todas as geleiras apresentaram os 3 ambientes devido a evolução do processo de retração das geleiras e formação do ambiente proglacial. Representam estágios sucessivos de maior ação paraglacial do que glacial (III) para a menor ação paraglacial do que glacial (I).

$\mathrm{O}$ ambiente proglacial marginal ao gelo (I) possui processos paraglaciais, intensos com a exposição recente de formas deposicionais glaciais, relacionadas a um ambiente proglacial marginal ao gelo. Os processos glaciais predominam no registro geomorfológico, com morainas frontais, laterais e latero-frontais e eskers.

$\mathrm{O}$ ambiente proglacial distal (II) possui formas deposicionais glaciais retrabalhadas e ainda há bastante aporte e desenvolvimento da drenagem glaciofluvial. Lagos perderam a conexão direta com a margem glacial. As morainas de recessão apresentam-se descontínuas na sua distribuição espacial linear.

$\mathrm{O}$ ambiente proglacial mais próximo ao mar e distante da geleira (III) é caracterizado pela presença de setores mais planos, extensas áreas depósitos lacustres e há a forte influência da atividade paraglacial e periglacial. Os lagos proglaciais apresentam-se sem conexão com a drenagem glaciofluvial. 
Tabela 3: Critérios metodológicos de identificação das formas no seu ambiente deposicional.

\begin{tabular}{|c|c|c|c|c|c|}
\hline $\begin{array}{l}\text { Forma de } \\
\text { relevo }\end{array}$ & $\begin{array}{c}\text { Ambiente } \\
\text { deposicional }\end{array}$ & Processo genético & $\begin{array}{c}\text { Associação sedimento/ } \\
\text { forma }\end{array}$ & Critério de identificação & Relevância \\
\hline $\begin{array}{c}\text { Moraina } \\
\text { Lateral e } \\
\text { latero-frontal }\end{array}$ & \begin{tabular}{|c|} 
Margem da \\
geleira (BENN \\
\& EVANS \\
$2010)$
\end{tabular} & \begin{tabular}{|c|} 
Origem subglacial, \\
englacial ou \\
supraglacial, envolve \\
deposição de \\
sedimentos, movimentos \\
de massa, deformação \\
glaciotectônica e outros \\
processos (BENN \& \\
EVANS, 2010).
\end{tabular} & $\begin{array}{c}\text { Caracterização } \\
\text { sedimentar de till } \\
\text { que varia conforme } \\
\text { o transporte ativo ou } \\
\text { passivo, constituída por } \\
\text { grãos grossos e mal } \\
\text { selecionados (BENNET } \\
\text { \& GLASSER, 1996; } \\
\text { BELL, 2013; ASSINE \& } \\
\text { VESELY, 2015). }\end{array}$ & $\begin{array}{l}\text { Possuem forma } \\
\text { assimétrica transversal } \\
\text { e/ou perpendicular à } \\
\text { geleira. } \\
\text { Podem ser de diversos } \\
\text { tipos e são classificados } \\
\text { de acordo com sua } \\
\text { localização em relação } \\
\text { à geleira (BENNET \& } \\
\text { GLASSER, 1996). }\end{array}$ & $\begin{array}{c}\text { Marca a } \\
\text { extensão de } \\
\text { uma geleira } \\
\text { (BENNET \& } \\
\text { GLASSER, } \\
\text { 1996). }\end{array}$ \\
\hline $\begin{array}{l}\text { Moraina } \\
\text { frontal de } \\
\text { avanço }\end{array}$ & $\begin{array}{c}\text { Limite máximo } \\
\text { de avanço de } \\
\text { uma geleira } \\
\text { (HAMBREY, } \\
\text { 1994). }\end{array}$ & \begin{tabular}{|} 
Originada da deposição \\
de sedimentos através \\
de movimentos de \\
massa e atividade \\
glaciotectônica (BENN \& \\
EVANS, 2010).
\end{tabular} & $\begin{array}{l}\text { Compostos por grãos } \\
\text { grossos, abundância de } \\
\text { clastos arredondados, } \\
\text { facetados, estriados } \\
\text { se formados } \\
\text { subglacialmente, } \\
\text { depositados pela } \\
\text { ação direta da } \\
\text { geleira (BENNET } \\
\text { \&GLASSER,1996). }\end{array}$ & $\begin{array}{l}\text { Apresentam crista } \\
\text { morâinica externa, } \\
\text { em geral arqueadas, } \\
\text { podem não estar bem } \\
\text { preservadas, refletem } \\
\text { a margem frontal da } \\
\text { geleira em (re) avanço } \\
\text { (HAMBREY, 1994; BENN } \\
\text { \& EVANS, 2010). }\end{array}$ & \begin{tabular}{|l} 
Registram \\
estágios \\
estacionários \\
de uma geleira \\
(HAMBREY, \\
1994; BENN \& \\
EVANS, 2010).
\end{tabular} \\
\hline $\begin{array}{l}\text { Moraina } \\
\text { frontal de } \\
\text { Recessão }\end{array}$ & $\begin{array}{c}\text { Margem } \\
\text { frontal da } \\
\text { geleira } \\
\text { (HAMBREY, } \\
\text { 1994; } \\
\text { BENNET \& } \\
\text { GLASSER, } \\
\text { 1996). }\end{array}$ & $\begin{array}{l}\text { Formada durante } \\
\text { estabilização da } \\
\text { frente da geleira, } \\
\text { durante uma recessão } \\
\text { glacial, empurrada } \\
\text { ou depositada por } \\
\text { um pequeno avanço } \\
\text { da geleira (BENN \& } \\
\text { EVANS, 2010). }\end{array}$ & $\begin{array}{c}\text { Constituída por grãos } \\
\text { grossos e baixa } \\
\text { seleção granulométrica, } \\
\text { abundância de clastos } \\
\text { arredondados, facetados, } \\
\text { estriados (HAMBREY, } \\
\text { 1994; BENNET \& } \\
\text { GLASSER, 1996). }\end{array}$ & $\begin{array}{l}\text { Perpendiculares ao } \\
\text { movimento do gelo, } \\
\text { na margem da geleira, } \\
\text { podem ter forma de } \\
\text { crista, cordão linear ou } \\
\text { montículos descontínuos } \\
\text { (HAMBREY, 1994; BENN } \\
\text { \& EVANS, 2010). }\end{array}$ & $\begin{array}{l}\text { Documenta } \\
\text { estágio } \\
\text { estacionário de } \\
\text { uma geleira, em } \\
\text { seu avanço ou } \\
\text { recuo. (BENN \& } \\
\text { EVANS, 2010). }\end{array}$ \\
\hline Esker & $\begin{array}{c}\text { Em contato } \\
\text { com o gelo } \\
\text { (HAMBREY, } \\
\text { 1994; } \\
\text { BENNETT \& } \\
\text { GLASSER, } \\
\text { 1996; BELL, } \\
\text { 2013). }\end{array}$ & $\begin{array}{c}\text { Ocorre pela corrente } \\
\text { de água subglacial, } \\
\text { depósitos de enchimento } \\
\text { das paredes de canais. } \\
\text { Corrente de água } \\
\text { na interface gelo/ } \\
\text { rocha, abaixo do gelo } \\
\text { ativo (BENNETT \& } \\
\text { GLASSER, 1996). }\end{array}$ & $\begin{array}{c}\text { Composição de grãos } \\
\text { variada, geralmente } \\
\text { grossos, cascalho e areia } \\
\text { glaciofluvial com grau de } \\
\text { arredondamento devido } \\
\text { ao transporte pela água } \\
\text { de degelo (HAMBREY, } \\
\text { 1994; BENNETT \& } \\
\text { GLASSER, 1996). }\end{array}$ & $\begin{array}{l}\text { Geralmente sinuoso. } \\
\text { Alguns possuem cristas } \\
\text { simples, outros podem } \\
\text { ser entrelaçados. Sua } \\
\text { orientação obedece a } \\
\text { curso de uma drenagem } \\
\text { (HAMBREY, 1994; } \\
\text { BENNETT \& GLASSER, } \\
\text { 1996). }\end{array}$ & $\begin{array}{c}\text { Indica fluxo } \\
\text { hídrico de canal } \\
\text { subglacial, base } \\
\text { termal úmida } \\
\text { e direção do } \\
\text { fluxo de gelo } \\
\text { (HAMBREY, } \\
\text { 1994; } \\
\text { BELL,2013) }\end{array}$ \\
\hline $\begin{array}{c}\text { Canais } \\
\text { entrelaçados }\end{array}$ & $\begin{array}{c}\text { Com ou } \\
\text { sem contato } \\
\text { com geleira } \\
\text { (SUGDEN \& } \\
\text { JOHN, } \\
\text { 1984). }\end{array}$ & $\begin{array}{l}\text { Fluvial com descarga de } \\
\text { água de degelo. }\end{array}$ & $\begin{array}{l}\text { Maior granulometria, } \\
\text { camadas estratificadas, } \\
\text { detritos refletem o } \\
\text { transporte pela água } \\
\text { (SUGDEN \&JOHN, } \\
\text { 1984). }\end{array}$ & $\begin{array}{l}\text { Canais entrelaçados } \\
\text { de água e leques } \\
\text { deposicionais (BENN \& } \\
\text { EVANS, 2010). }\end{array}$ & $\begin{array}{c}\text { Evidencia } \\
\text { avanço e recuo } \\
\text { da geleira } \\
\text { (ASSINE \& } \\
\text { VESELY, 2015). }\end{array}$ \\
\hline
\end{tabular}

\subsubsection{Mapeamento geomorfológico do ambiente proglacial da geleira Ecology}

$\mathrm{Na}$ área frontal da geleira Ecology (Figura 3) foram identificados: morainas latero-frontais, eskers, morainas frontais, canais com água de degelo, alguns destes entrelaçados. As morainas latero-frontais encontram-se no setor norte da geleira Ecology, indicando a extensão máxima da geleira. Conforme Bennet \& Glasser (1996), essas feições se formam durante a estabilização frontal da geleira e podem apresentar dimensões variadas.

A moraina latero-frontal ao norte da Ecology, possui a crista alongada e alinhamento paralelo ao fluxo da geleira. Estas morainas, laterais e latero-frontais, com aproximadamente $1 \mathrm{~km}$ de comprimento, em alguns 
pontos se apresentam-se com mais de 30 metros de altura. A elevação apresentada pelo cordão morâinico sugere uma maior espessura para essa geleira no passado, que, ao que tudo indica, projetava-se sobre a Baía do Almirantado (VIEIRA et al., 2005).

Os eskers foram identificados nas áreas proglaciais expostas nas últimas duas décadas. Estes indicam a direção do fluxo de gelo e remetem a presença de antigos canais de drenagem subglacial, assim como denotam Hambrey (1994), Bennet \& Glasser (1996) e Bell (2013). Enquanto os eskers estavam sendo formados na geleira, os canais fluíam para a margem desta, como destacado por Sugden \& John (1976), pois a formação dessas feições ocorre pelo preenchimento das paredes de canais em gelo ativo (BENNET \& GLASSER, 1996).

Em setores distais à geleira Ecology, livres de cobertura de gelo há mais tempo, evidenciam-se atividades paraglaciais. Ballantyne (2002) ressalta a cobertura de vegetação como indicador de estabilidade do terreno.

$\mathrm{Na}$ bacia da geleira Ecology, em resposta a retração da mesma, há a formação da laguna proglacial Ecology, a qual se conecta à Baía do Almirantado. Dessa forma, trata-se de uma geleira mista, com término em água e parte em terra. A influência marítima ocorre devido à maré. Esse corpo de água possui afloramentos rochosos em áreas rasas e através da dinâmica da maré, a laguna Ecology conecta-se de forma parcial com a geleira Ecology ao sul (PETLICKI et al., 2017).
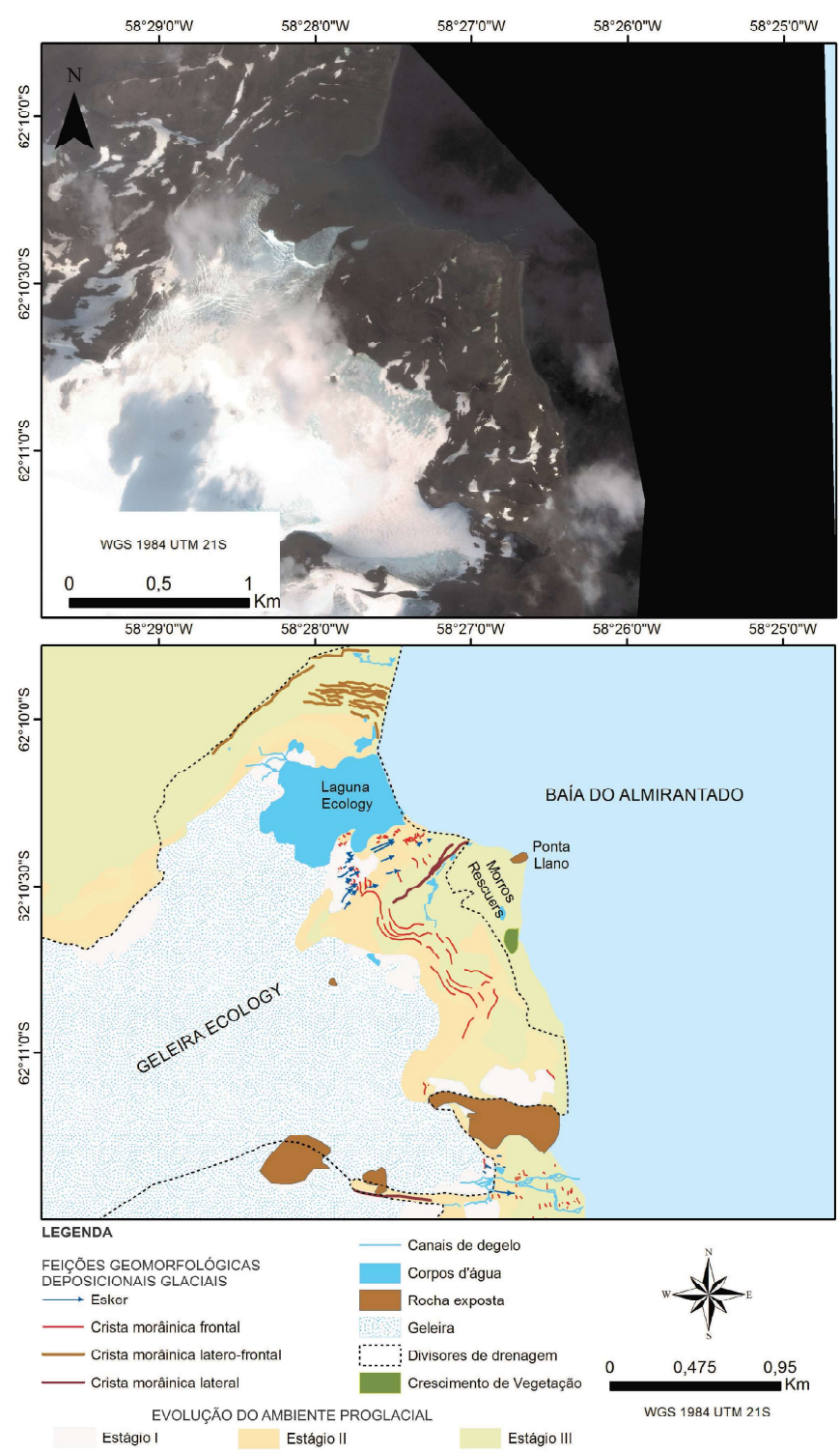

Figura 3 - Mapeamento geomorfológico das feições deposicionais de meso-escala da área proglacial da geleira Ecology. Estágios vão da menor para a maior influência da ação paraglacial comparativamente à glacial (I-III) na caracterização dos processos geomorfológicos do sistema proglacial. 
Os eskers, lagos e canais de drenagem se encontram atualmente em contato com a geleira Ecology e estendem-se sobre o ambiente I. Enquanto que corpos de água e morainas frontais de maiores dimensões estão no ambiente II. As morainas latero-frontais, ao norte e moraina lateral ao sul da geleira, estão no ambiente III (Figura 3). O setor central da frente da geleira não apresenta os 3 ambientes sucessionais, mas o setor norte apresenta, pois o término é em ambiente lagunar.

\subsubsection{Mapeamento geomorfológico do ambiente proglacial da geleira Sphinx}

A geleira Sphinx (Figura 4), ao sul da geleira Ecology, possui depósitos morâinicos ao sul, com uma zona proglacial medindo cerca de 1.200 metros (de extensão) no sentido N-S e 800 metros E-W (RACHLEWICZ, 1999). Com base no mapeamento geomorfológico, observa-se que estas morainas laterais se encontram descontínuas e retrabalhadas. Ao norte da geleira verificou-se a presença de moraina lateral. $\mathrm{Na}$ área de contato com o gelo frontal não é possível observar feições deposicionais morâinicas. Em setores distais (ambientes II e III), há canais de drenagem, morainas frontais, lagos e eskers (Figura 4). Os ambientes II e III são os mais extensos.

Os resultados corroboram com Rachlewicz (1999), que ressalta a ocorrência de morainas com altura superior a 20 metros. Na zona próxima à margem do gelo há morainas que podem atingir 20 metros de altura. Os canais entrelaçados, lagos e eskers são verificados no setor proglacial norte (Figura 4).

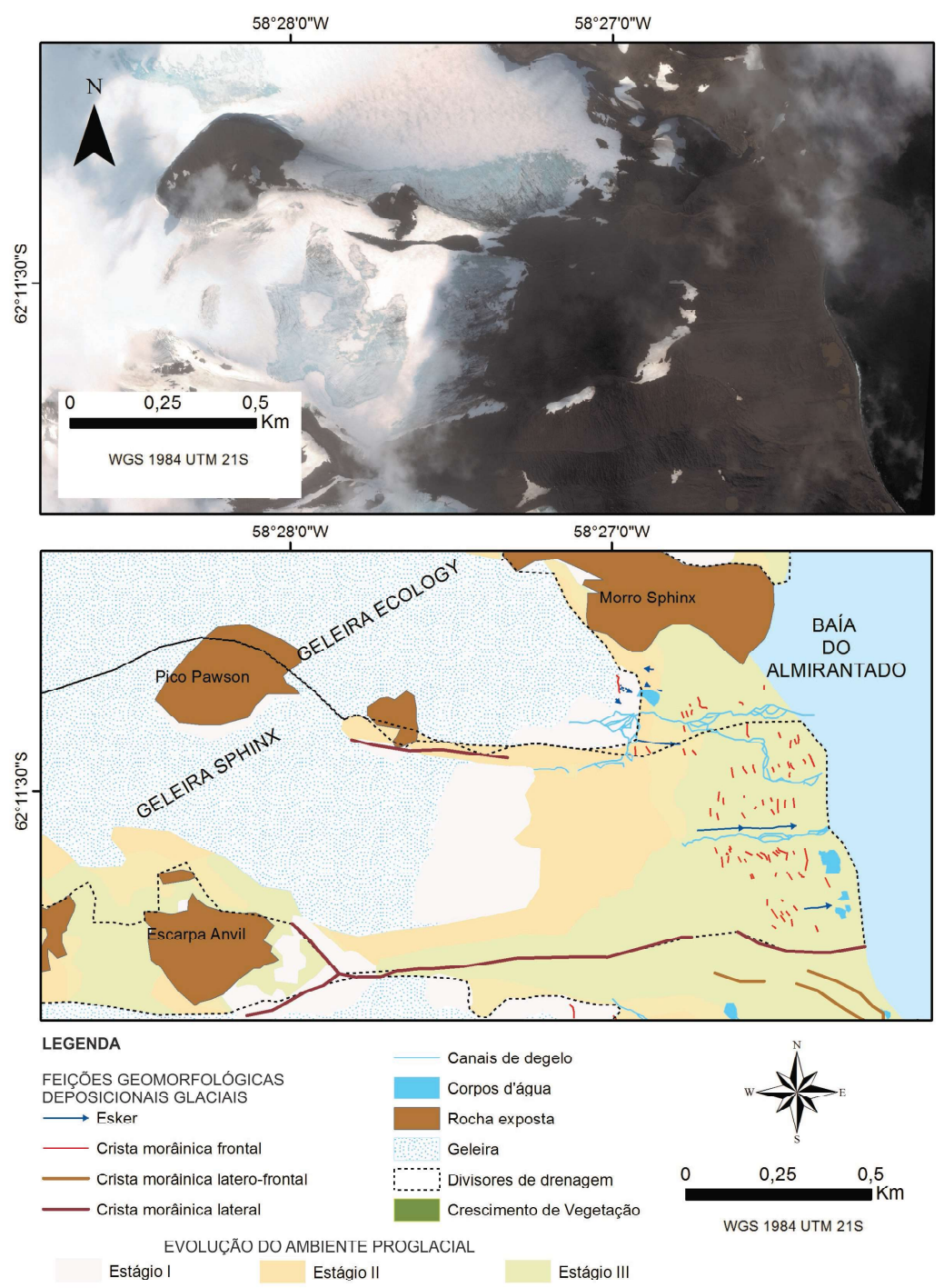

Figura 4 - Mapeamento geomorfológico das feições deposicionais de meso-escala da área proglacial da geleira Sphinx. Estágios vão da menor para a maior influência da ação paraglacial comparativamente à glacial (I-III) na caracterização dos processos geomorfológicos do sistema proglacial. 
As morainas laterais ao sul e ao norte da geleira Sphinx tiveram sua formação entre 2000-2017. Enquanto que a moraina lateral ao norte da geleira é formada no período de 1979-2000.

O processo de retrabalhamento de feições nessa área proglacial é evidenciado onde há influência de água de degelo de geleiras e a exposição a processos subaéreos. Os canais entrelaçados transportam e retrabalham sedimentos subglaciais e subaéreos ao longo da geleira Sphinx até a baía do Almirantado, assemelhando-se ao que ocorre na geleira Baranowski, situada ao sul de Sphinx (BREMER, 2008).

A geleira Sphinx é limitada por maciços de rochas expostas, e sua área proglacial é formada por rochas resistentes a interferência mecânica da ação glacial. No local de encontro entre as bacias das geleiras Sphinx e Baranowski, há formações rochosas como a Ágat Point. $\mathrm{Na}$ área proglacial da geleira Baranowski há feições morâinicas, algumas retrabalhadas por ação hídrica e água proveniente da fusão de gelo. $\mathrm{O}$ escoamento de água de degelo sobre encostas íngremes causa instabilidade e movimentos de massa (RACHLEWICZ, 1999).

A moraina lateral ao sul da geleira Sphinx e eskers estão sob influência predominante de processos paraglaciais (ambiente I) (Figura 4).

\subsubsection{Mapeamento geomorfológico do ambiente proglacial da geleira Baranowski}

A geleira Baranowski (Figura 5) apresentou acelerada retração na década de 1990, de acordo com Birkenmajer (2002) e Perondi (2018). Como resultado desta retração, evidencia-se um amplo ambiente proglacial, com aproximadamente 1000 metros de extensão, e com a presença de feições morâinicas em sua área marginal ao gelo e água oriunda de fusão glacial (RACHLEWICZ, 1999).

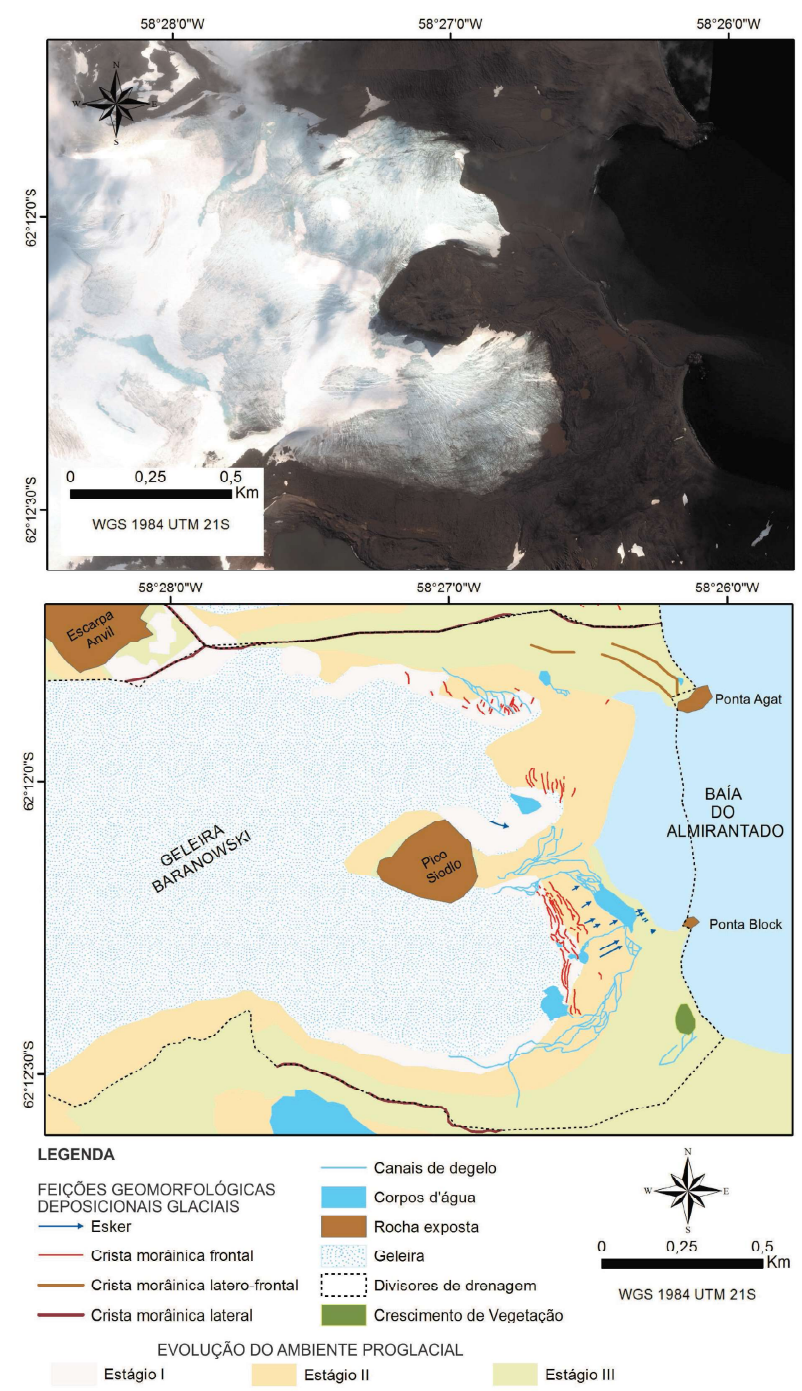

Figura 5 - Mapeamento geomorfológico da das feições deposicionais de meso-escala área proglacial da geleira Baranowski. Estágios vão da menor para a maior influência da ação paraglacial comparativamente à glacial (I-III) na caracterização dos processos geomorfológicos do sistema proglacial. 
$\mathrm{Na}$ área proglacial é possível observar morainas laterais ao norte e ao sul da geleira (Figura 5). Essas feições são encontradas às margens das geleiras e sua formação ocorre por deposição de sedimentos (BENN \& EVANS, 2010). Essas morainas orientadas perpendicularmente à geleira indica o ponto de avanço máximo da geleira, conforme afirma BENNET \& GLASSER (1996). Também foram evidenciadas morainas latero-frontais retrabalhadas (Figura 5).

As cristas morâinicas laterais se estendem ao longo da borda sul da geleira Baranowski, onde há maior espaçamento nas adjacências da costa marítima.

A área livre de gelo da geleira Baranowski apresenta diversos canais de água de degelo e alimentam os lagos proglaciais.

A linha frontal da geleira forma um penhasco, o qual na década de 1970 era fortemente influenciado e modelado pela ação litorânea (RACHLEWICZ, 1999).

Eskers e canais de drenagem e lagos são formados em contato com o gelo, alimentados por água de degelo, os quais se ligam através de canais entrelaçados aos demais lagos desta área proglacial. Os corpos de água próximos de geleiras são mantidos por blocos que se desprendem, correntes de água subglaciais ou englaciais (ASSINE \& VESELY, 2002). Próximo à linha de costa percebe-se a presença de núcleos vegetacionais (musgos e liquens).

No local de encontro entre as bacias das geleiras Sphinx e Baranowski há formações rochosas como a Ágat Point. Os resultados vão ao encontro do que evidencia Rachlewicz (1999), o qual traz as feições morâinicas retrabalhadas por ação hídrica proveniente de fusão de gelo e movimentos de massa (RACHLEWICZ, 1999).

O setor sul da frente da geleira possui os 3 ambientes sucessionais, mas o setor norte não apresenta, pois o término é em ambiente lagunar. $\mathrm{O}$ ambiente I possui geoformas como recentes morainas frontais, moraina lateral e eskers bem preservados. Enquanto que, lagos e canais glaciofluviais, os mais distais, e os eskers distais, apresentam-se no ambiente II. As morainas laterais ao sul e ao norte da geleira, além de morainas latero-frontais e alguns eskers pouco preservados estão dispostos no ambiente III (Figura 5).

\subsubsection{Mapeamento geomorfológico do ambiente proglacial da geleira Tower}

A geleira Tower, localizada ao sul da geleira Baranowski (Figura 6), apresenta elevação de aproxi- madamente 366,9 metros (MARSZ, 1985). Vieira et al. (2005) argumenta que na zona proglacial desta geleira, o material depositado é constituído por depósitos de till (detritos basais). A moraina lateral, ao sul da geleira Tower, e a moraina frontal são formadas durante 2000-2017, enquanto que morainas frontais, lagos sem contato com o gelo formaram-se durante 1979-2000 (Figura 6 e 8).

Em setores distais à geleira, há pontos com a presença de núcleos de vegetação e lagos entrelaçados, assim como traz Bremer (2008) ao ressaltar a presença de musgos e liquens, pequenos lagos e sistema de drenagem dinâmico. A geleira possui um ambiente proglacial com altos valores de declividade e há a influência da ação gravitacional em setores íngremes. Os ambientes II e III predominam em área e apresentam canais entrelaçados (Figura 6).

\subsubsection{Mapeamento geomorfológico do ambiente proglacial da geleira Windy}

A geleira Windy (Figura 7) possui uma zona proglacial frontal abrangendo o ambiente I apenas. O retrabalhamento dos depósitos glaciais recém expostos ocorre pela água de degelo e pluvial. Identificou-se morainas laterais, revelando a extensão da geleira para o noroeste (Figura 8) e inúmeros eskers nos ambientes II e III existentes no setor ao noroeste.

Morainas latero-frontais não foram identificadas na geleira Windy, Tower e Sphinx, mas foram observadas nas geleiras Baranowski e Ecology, em ambos os casos apresentando características de retrabalhamento por sua descontinuidade na área proglacial da geleira Ecology e Baranowski. O término destas feições ocorre no mar. A moraina latero-frontal externa localizada na extremidade da laguna Ecology é comumente coberta pela ação da maré e correntes (VIEIRA et al., 2005). Os eskers mapeados foram expostos entre 2000-2017.

Há outras feições deposicionais na área proglacial de algumas geleiras da área de estudo que não foram possíveis de identificar, possivelmente pelo retrabalhamento dessas formas. Na área livre de gelo da geleira Ecology foram identificados em trabalhos passados presença de flutings (VIEIRA et al., 2005; ROSA et al., 2006), bem como na área proglacial da geleira Sphinx (RACHLEWICZ, 1999; BREMER, 2008). As morainas laterais indicadas próximas à costa por Rachlevicz (1999) não foram identificadas neste estudo. 
Perondi C. et al.
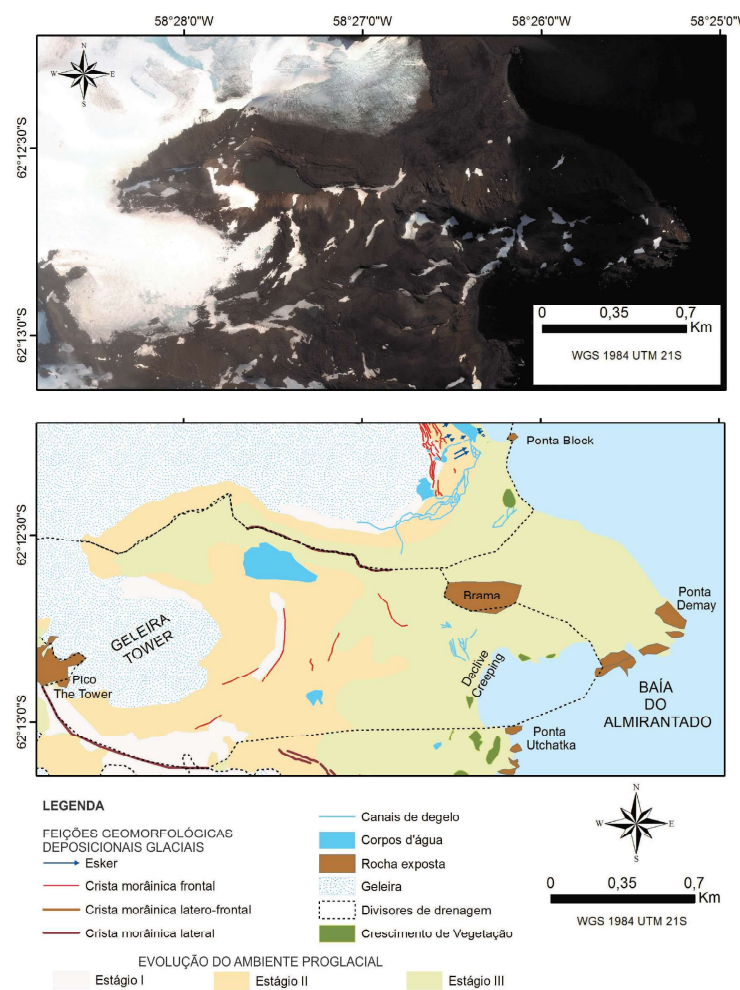

Figura 6-Mapeamento geomorfológico das feições deposicionais de meso-escala da área proglacial da geleira Tower. Estágios vão da menor para a maior influência da ação paraglacial comparativamente à glacial (I-III) na caracterização dos processos geomorfológicos do sistema proglacial.

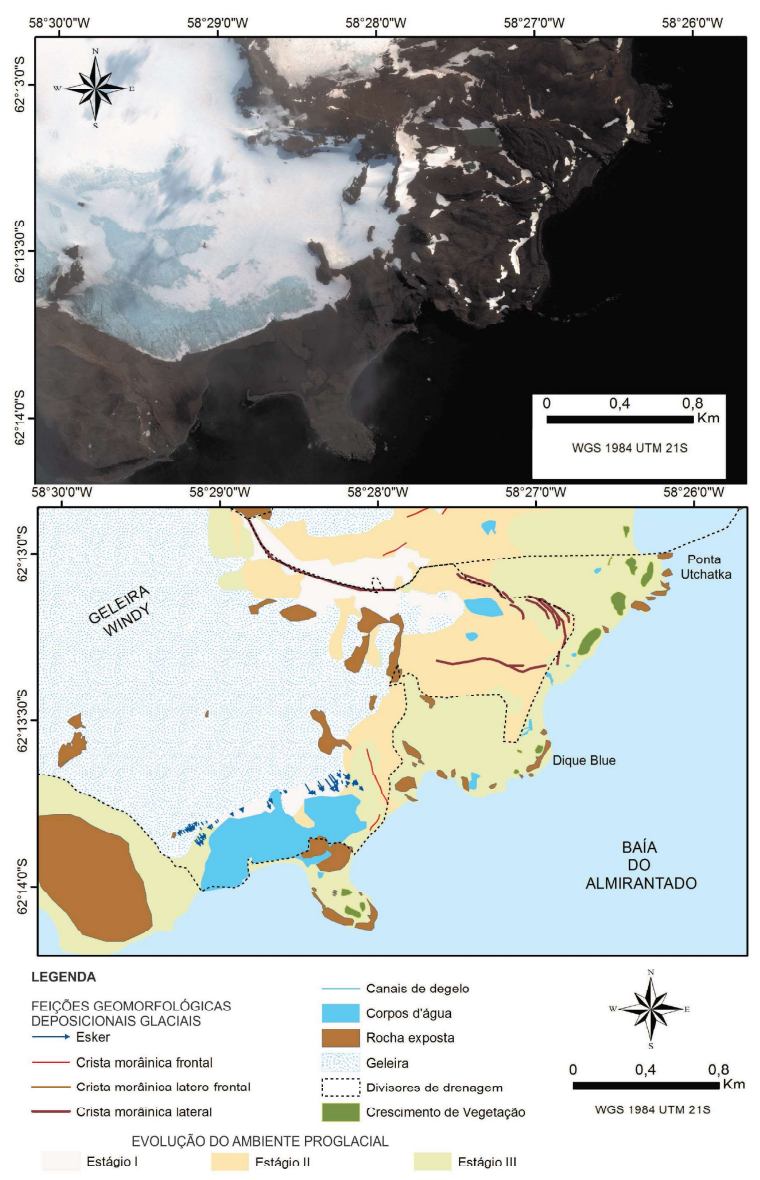

Figura 7 - Mapeamento geomorfológico das feições deposicionais de meso-escala da área proglacial da geleira Windy. Estágios vão da menor para a maior influência da ação paraglacial comparativamente à glacial (I-III) na caracterização dos processos geomorfológicos do sistema proglacial. 


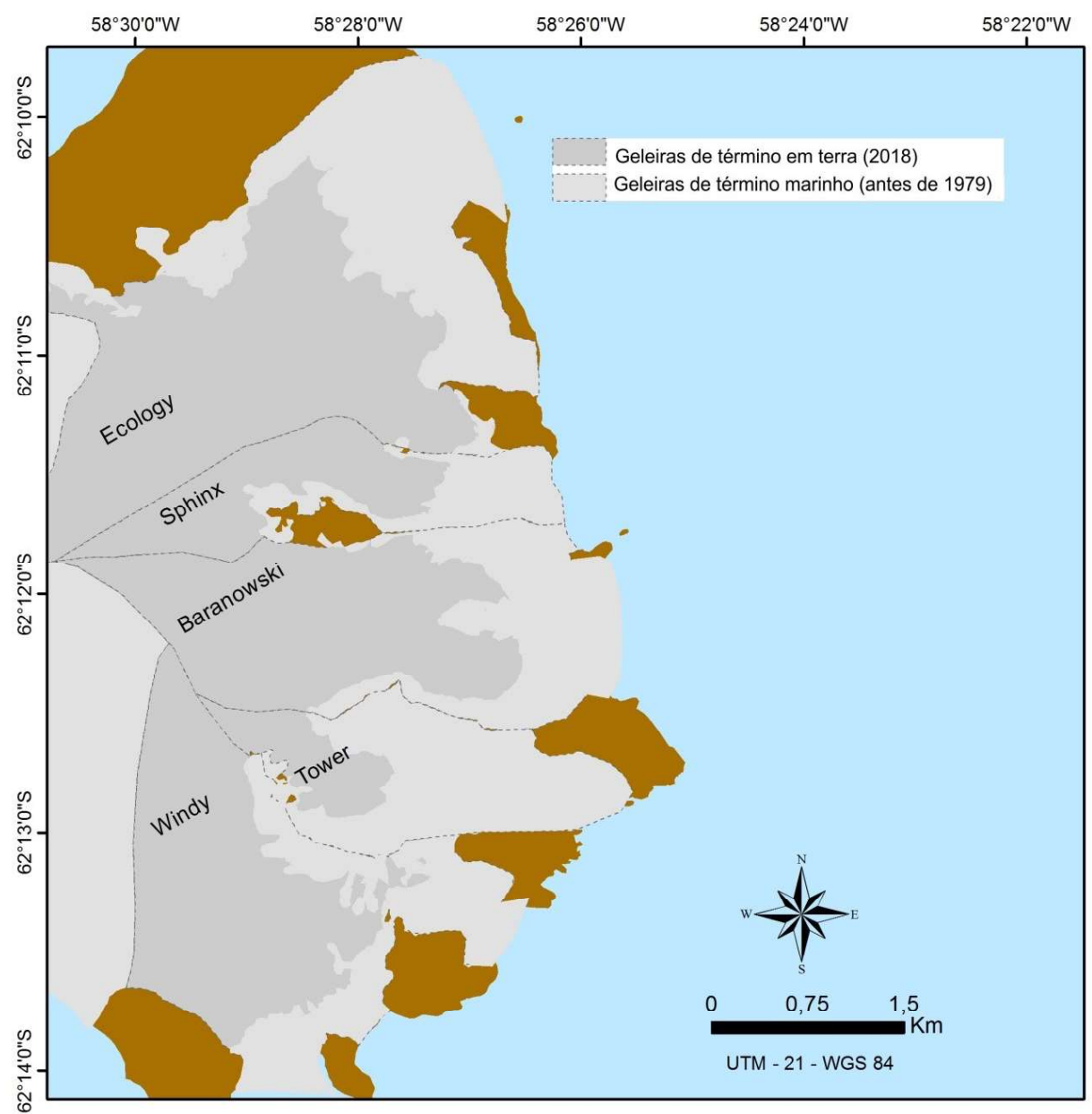

Figura 8-Reconstrução paleoglaciológica das geleiras Ecology, Baranowski, Sphinx, Tower e Windy a partir da identificação dos estágios I, II e III.

\section{Considerações Finais}

Os produtos geomorfométricos e mapeamento geomorfológico trouxeram dados que possibilitam inferir mudanças ambientais que vêm ocorrendo na área de estudo, tais como a ocorrência de processos erosivos paraglaciais, mudanças morfológicas das geleiras e de suas áreas livres de gelo formadas a partir da retração das mesmas.

Nas áreas proglaciais verificam-se feições glaciais deposicionais, como eskers, morainas frontais, laterais e latero-frontais, também há presença de canais com água de degelo, entrelaçados e outros não entrelaçados, lagos e lagunas.

As áreas livres de gelo recentes são suscetíveis à exposição subaérea das formas de relevo e seu retrabalhamento por ação eólica e hídrica. Foram identificadas atividades periglaciais e paraglaciais, esta é intensa nos 3 ambientes com processos de ravinamentos, retrabalhamento de cordões morâinicos descontínuos.
As formas de relevo deposicionais glaciais estão sob influência de alta atividade paraglacial, mas há predomínio conforme se distancia das margens frontais das geleiras (ambientes proglaciais II e III), onde a influência glacial é predominante na paisagem (ambiente proglacial I). As geleiras Tower e Sphinx possuem os ambientes I de menores dimensões, devido ao perfil mais íngreme. A geleira Windy possui apenas o ambiente I na sua frente, no setor a noroeste há os ambientes I, II e III.

A ação periglacial e paraglacial é identificada em todos os ambientes, com destaque para o ambiente III, com a presença de processos de ravinamentos, retrabalhamento de cordões morâinicos descontínuos e a presença de núcleos de vegetação sobre áreas rochosas, além de marcas da ação do degelo na superfície.

A ação paraglacial é mais intensa com o aumento da declividade, menor distância da frente atual, maior aporte de água de degelo pela geleira e com a maior disponibilidade de feições de relevo com sedimentos dispostos em um perfil íngreme e instável (como mo- 
rainas e eskers). Com a distância da geleira os depósitos morâinicos e eskers estão sob condições mais estáveis, pois há a diminuição do perfil íngreme, como o tempo, e há cobertura vegetal se desenvolvendo.

As feições mapeadas resultaram na reconstrução glacial e a descontinuidade da moraina latero-frontal mais externa evidenciaram condições de término marinho para todas as geleiras. A presença de eskers e pavimento estriado, evidenciado por Vieira et al. (2005), caracteriza condições termo-basais úmidas para as geleiras na área de estudo. O processo de retração das geleiras estará relacionado com o aumento da distância de corpos lacustres, e, desta forma, a diminuição da recarga pelo aporte de água de degelos sazonal. Os lagos tendem a ficar mais distantes das linhas de frente das geleiras e diminuir de extensão com o progressivo processo de retração.

\section{Agradecimentos}

A FAPERGS, o CNPq e o Programa Antártico Brasileiro (PROANTAR) forneceram o suporte para essa pesquisa.

\section{Referências Bibliográficas}

ANDRADE, A. M. Delimitação de geoambientes na península Potter, ilha Rei George (Antártica Marítima), utilizando dados COSMO-SkyMed e QuickBird. Dissertação (Mestrado em Sensoriamento Remoto), Universidade Federal do Rio Grande do Sul, Porto Alegre. 2013. 150 p.

ASSINE, M. L.; VESELY, F. F. (2008). Ambientes Glaciais. In: PEDREIRA. A.J.P. (org.). Ambientes de Sedimentação Siliciclástica do Brasil. Editora Beca, São Paulo: p. 24-51.

BALLANTYNE, C. K. Paraglacial geomorphology. Quaternary Science Reviews, v. 21, p. 1935 - 2017. 2002. DOI: 10.1016/ S0277-3791(02)00005-7

BELL, R. C. Glacial Systems and Landforms: A Virtual Interactive Experience. London: Anthen Press, 2013. 136 p.

BENN, D. I.; EVANS, D. J. A. Glaciers and Glaciation. $2^{\mathrm{a}}$ ed. London: Hodder Education. 2010. 802p.

BENNETT M.R.; GLASSER, N.F. Glacial Geology - Ice Sheets and Landforms. England: John Wiley \& Sons Ltd, 1996. 364 p.

BIRKENMAJER, K. Discovery of Pliocene glaciation on King George Island, South Shetland Islands (West Antarctica). Bulletin de L'Academie Polonaise des Sciences, v. 27, p. 5967. 1980a.
BIRKENMAJER, K. Tertiary volcanic-sedimentary succession at Admiralty Bay, King George Island (South Shetland Islands,Antarctica). Studia Geologica Polonica, v. 64, p. 8-65. 1980b.

BIRKENMAJER, K. Cenozoic Phases of Block-Faulting on King George Island (South Shetland Islands, Antarctica). Bulletin de L'Academic Polonaise des Sciences, v. 30, n. 1/2, p. 21-32. 1983 .

BIRKENMAJER, K. (1989). King George Island. In: DALZIEL, I.W.D.; BIRKENMAJER, K.; MPODOZIS, C., RAMOS, V.A.; THOMSON, M.R.A. (orgs): Tectonics of the Scotia Arc. Antarctica. American Geophysical Union, Punta Arenas: p. 144-121.

BIRKENMAJER, K. (1991). Tertiary Glaciation in the South Shetland Islands, West Antarctica: Evaluation of Data. In: THOMSON, M.R.A.; CRAME, J.A.; THOMSON, J.W. (orgs), Geological Evolution of Antarctica. Cambridge University Press, Cambridge: p. 627-632.

BIRKENMAJER, K. Geology of the northern coast of King George Island, South Shetland Islands (West Antarctica). Studia Geologica Polonica, v. 110, p. 7-26. 1997.

BIRKENMAJER, K. Retreat of Ecology Glacier, Admiralty Bay, King George Island (South Shetland Islands, West Antarctica). 1956-2001. Bulletin of Polish Academy of Sciences: Earth Sciences, v. 50, n.1, p 5-19. 2002.

BONADA, B.; ROSA, K. K.; ANDRADE, A. M. Caracterização geomorfológica das áreas livres de gelo em resposta da tendência de retração da geleira Polar Club, Península Potter, Ilha Rei George, Antártica. Revista Brasileira de Geomorfologia, v. 19, 149-167. 2018.

BOULTON, G.S.; SMITH, G. D.; JONES, A. S.; NEWSOME. J. Glacial geology and glaciology of the last mid-latitude ice sheets. Journal of Geological Society of London, v. 142, p. 447-474. 1985. DOI: 10.1144/gsjgs.142.3.0447

BRAUN, M. Ablation on the Ice Cap of King George Island (Antarctica). PhD. Dissertation, Albert-Ludwigs-Universitat Feiburg, 165 p. 2001.

BREMER, U. F. Solos e Geomorfologia da Borda Leste da Península Warszawa, Ilha Rei George, Antártica Marítima. Tese (Doutorado em Solos e Nutrição de Plantas). Universidade Federal de Viçosa, Viçosa. 2008. 135 p.

CUFFEY, K. M.; CONWAY, H.; GADES, A. M.; HALLET, B.; LORRAIN, R.; SEVERINGHAUS, J.P.; STHEIG, E. J.; VAUGHN, B.; WHITE, J.W.C. Entrainment at cold 
glacier beds. Geology, v. 28, p. 351-354. 2000. DOI: 10.1130/0091-613(2000)28<351:EACGB $>2.0 . C O ; 2$

CURL, J.E. A glacial history of the South Shetland Islands, Antarctica. Ohio State University, Institute of Polar Studies Report, v. 63, 129 p. 1980.

DAVIES, B.J.; GOLLEDGE, N.R.; GLASSER, N.F.; CARRIVICK, J.L.; LIGTENBERG, S.R.M.; BARRAND, N.E.; VAN DEN BROEKE, M.R,; HAMBREY, M.J.; SMELLIE, J.L. Modelled glacier response to centennial temperature and precipitation trends on the Antarctic Peninsula. Nature Climate Change, v. 4, p. 993-998. 2014. DOI:10.1038/nclimate2369

FERREIA, A. B. Os ambientes periglaciários e o significado das manifestações periglaciárias herdadas. Finisterra Revista Portuguesa de Geografia, v. 26, n. 51, p. 84-105. 1991. DOI: 10.18055/Finis 1910

GLASSER, N. F.; SCAMBOS T. A.; BOHLANDER J.; TRUFFER M.; PETTIT, E.; DAVIES, B. J. From ice-shelf tributary to tidewater glacier: continued rapid recession, acceleration and thinning of Röhss glacier following the 1995 collapse of the Prince Gustav ice shelf, Antarctic Peninsula. Journal of Glaciology, v. 57, p. 397-406. 2011.

GROENEWEG, W. J.; BEUNGK, F. F. (1992). The Petrography and Geochemistry of the King George Island Supergroup and the Admiralty Bay Group Volcanics, South Shetland Islands. In: LÓPEZ-MARTINEZ, J. (orgs.). Geología de la Antártida Occidental. Salamanca, España, p. 43-60.

HATtestrand, C.; KOLKA, V.; StROEVEN, A. The keiva ice marginal zone on the Kola península, NW Rússia - a key component for reconstructing the paleoglaciology of the northeastern fennoscandian ice sheet. Boreas, v. 36, p. $352-$ 370. 2007.

HAMBREY, M. Glacial Environments. London: UCL Press, 1994. $296 \mathrm{p}$.

HUBBARD, B.; GLASSER, N. Field Techniques in Glaciology and Glacial Geomorphology. Inglaterra: John Wiley \& Sons Lda, 2005. 412p.

KLEMAN, J.; HATTESTRAND, C.; STROEVEN, A. P.; JANSSON, K. J.; ANGELIS, H.; BORGSTROM, I. (2006). Reconstruction of Paleo-ice Sheets-inversion of their Glacial Geomorphological Record. In: KNIGHT, P. G. (org). Glacier Science and Environmental Change. Blackwell Publishing Ltd. Oxford, p.192-198.

MARSZ, A. A. Charakterystyka Fizyczno-geograficzna Obszarów Lodowych w Otoczeniu Zatoki Admiralicji Jako
Podstawa Rozpoznania Fragmentu Ekosystemu. Gdynia, Manuscript Wyższa Szkoła Morska, 1985. 146 p.

NAPIERALSKI, J.; HARBOR, J.; LI, Y. K. Glacial geomorphology and Geographic Information Systems. Earth Science Review, v. 85, p. 1-22. 2007. DOI: 10.1016/j. earscirev.2007.06.003

OTTO, J. C.; SMITH, M. J. Geomorphological mapping. British Society for Geomorphology. v. 6, p. 1-10. 2013.

PERONDI, C. Retração das Geleiras da Margem Leste do Campo de Gelo Warszawa, Ilha Rei George, Antártica. Dissertação (Mestrado em Geografia). Universidade Federal do Rio Grande do Sul, Porto Alegre, 2018. 123p.

PETLICKI, M.; SZILLO, J.; MACDONELL, S.; VIVERO, S.; BIALIK. Recent deceleration of the ice elevation change of Ecology glacier (King George Island, Antarctica). Remote Sensing, v. 9, n. 6. 2017. DOI: 10.3390/rs9060520

PETSCH, C. Evolução Hidro Geomorfológica da Zona Proglacial da Geleira Collins, Ilha Rei George, Antártica. Tese (Doutorado em Geografia). Instituto de Geociências. Universidade Federal do Rio Grande do Sul. Porto Alegre. 2018. $120 \mathrm{p}$.

PUNKARI, M. Glacial flow systems in the zone of confluence between the Scandinavian and Novaya Zemlya Ice Sheets. Quaternary Science Reviews, v. 14, p. 589-603. 1995. DOI: 10.1016/0277-3791(95)00026-L

RACHLEWICZ, G. Glacial relief and deposits of the western coast of Admiralty Bay, King George Island, South Shetlands Islands. Polish Polar Research, v. 20, n. 2, p. 89 - 130. 1999.

ROSA, K. K.; VIEIRA, R.; SIMÕES, J. C. Dinâmica glacial e características sedimentares resultantes na zona proglacial da geleira Ecology - Baía Do Almirantado, Ilha Rei George Antártica. Revista Brasileira de Geomorfologia, n 2, p. 51 - 60. 2006. DOI: $10.20502 /$ rbg.v7i2.78

ROSA, K. K.; VIEIRA, R.; FERNADEZ, G, B.; SIMÕES, F. L.; SIMÕES, J. C. Glacial landforms and glaciological processes of the temperate Wanda glacier, South Shetlands. Investigaciones Geográficas, v. 43, p. 3 - 16. 2011.

ROSA, K. K. Dinâmica Glacial, Sedimentológica e Variações Ambientais em Geleiras na Enseada Martel, Ilha Rei George, Shetlands do Sul. Tese (Doutorado em Ciências), Universidade Federal do Rio Grande do Sul, Porto Alegre. 2012. 184 p.

ROSA, K.K.; MENDES, C. W.; VIEIRA, R.; DANI, N.; SIMÕES, J.C. Análise morfométrica do setor norte da Baía do Almirantado, Ilha Rei George, Shetlands do Sul, Antártica. 
Boletim de Geografia, v. 32, n. 1, p. 52-61. 2014. DOI: 10.4025/ bolgeogr.v32il.18710

SIMÕES, C. L. Retração das geleiras Drummond e Widdowson em respostas às recentes mudanças ambientais na península Antártica (1957-2016). Dissertação (Mestrado em Geografia). Universidade Federal do Rio Grande do Sul, Porto Alegre. 2017. 79p.

SLAYMAKER, O. Criteria to distinguish between periglacial, proglacial and paraglacial environments. Quaestiones Geographicae, v. 30, p. 85 - 94. 2011. DOI: 1 0.2478/v10117011-0008-y

SUGDEN, D. E.; JOHN B. S. Glaciers and Landscape. London: Edward Arnold Ltda, 1976. 376 p.

SUGDEN, D. E.; JOHN B. S. Glaciers and Landscape: A Geomorphological Approach. 2a ed. London: Editora Edward Arnold, 1984. 376 p.
TOKARSKI, A. K. Structural events in the south Shetlands Islands (Antarctica). III. Barton Horst, King George Island. Studia Geologica Polonica, v. 90, p. 7-38. 1987.

THOMSON, M. R. A.; PANKHURST, R. J.; CLARKSON, P.D. 1983. The Antarctic Peninsula a Late Mesozoic - Cenozoic arc (Review). In: OLIVER, R. L.; JAMES, P. R.; JAGO, J. B. (orgs) Antarctic Earth Science. Australian Academy of Science,Cambridge: p. 328-333.

VIEIRA, R.; ROSSATO, M. S.; AQUINO, F. E.; SIMÕES, J. C. Feições morfológicas associadas ao ambiente de deglaciação da geleira Ecology, Ilha Rei George, Antártica. Revista Brasileira de Geomorfologia, v 6, n 2, p. 51-64. 2005. DOI: 10.20502/ rbg.v6i2.51

WESSEL, B. TanDEM-X Ground Segment - DEM Products Specification Document, EOC, DLR, Oberpfaffenhofen, Germany. Public Document TD-GS-PS-0021, v. 3.2, p. 1-46, 2018. 